\title{
Robotic-assisted unicompartmental knee arthroplasty: a review
}

\author{
Pei Liu', Fei-fan Lu², Guo-jie Liu', Xiao-hong Mư ${ }^{3}$, Yong-qiang Sun ${ }^{1}$, Qi-dong Zhang ${ }^{4}$, Wei-guo Wang ${ }^{4}$ and \\ Wan-shou Guo ${ }^{4^{*}}$
}

\begin{abstract}
Purpose: Presented here is an up-to-date review concerning robotic-assisted unicompartmental knee arthroplasty (rUKA), including its rationale, operative system, pros and cons.

Methods: We did a systematic research in electronic databases, including PubMed, Cochrane Library, Web of Science, and Embase up to March 30, 2020 to retrieve literature pertaining to rUKA. The search strategies "(robotic* AND knee arthroplasty OR knee replacement)" and "(knee arthroplasty OR knee replacement NOT total)" were used. Studies describing rUKA and clinical trials, dry bone or cadaveric researches regarding technologies, positioning, alignment, function, or survivorship of implants were included in this review. All retrieved studies were first browsed for eligibility on the basis of title and abstract, and the selected studies were further evaluated by reading full text for final inclusion.

Results: Robotic-assisted technology has been found to increase the accuracy of bone preparation and implant placement, reduce technical variability and outliers, and enhance reproduction of limb alignment. Additionally, early clinical outcomes were excellent, but mid-term follow-up showed no superiority in component survivorship. The potential drawbacks of the robotic-assisted technology include relatively-low time- and cost-effectiveness, development of some rUKA-related complications, and lack of support by high-quality literature.

Conclusion: This review shows that rUKA can decrease the number of outliers concerning the optimal implant positioning and limb alignment. However, due to absence of extensive studies on clinical outcomes and long-term results, it remains unclear whether the improved component positioning translates to better clinical outcomes or long-term survivorship of the implant. Nevertheless, since an accurate implant position is presumably beneficial, robotic-assisted technology is worth recommendation in UKA.
\end{abstract}

Keywords: Robotic assisted surgery, Robotic, Unicompartmental knee arthroplasty

\section{Introduction}

Unicompartmental knee arthroplasty (UKA) is a promising procedure since it preserves bone and ligaments, shortens hospital stay time, reduces postoperative morbidity, and enhances patient's satisfaction compared with total knee arthroplasty (TKA) in the treatment of endstage symptomatic anteromedial osteoarthritis and focal

\footnotetext{
* Correspondence: cjfh2020@163.com

${ }^{4}$ Department of Orthopaedic Surgery, Beijing Key Lab Immune-Mediated Inflammatory Diseases, China-Japan Friendship Hospital, No. 2, Yinghuadong Road, Chaoyang District, Beijing 100029, China

Full list of author information is available at the end of the article
}

osteonecrosis of knee [1, 2]. Nonetheless, UKA is a significantly demanding technique. Up to $30 \%$ of UKAs using the standard operative technique resulted in inaccurate implantation [3]. In addition, it is challenging to achieve precise limb alignment with conventional techniques, particularly in minimally invasive procedures. Even skilled surgeons may not consistently attain accurate alignment [4]. Investigations by Keene and Cobb demonstrated that, in as many as $40 \%$ to $60 \%$ cases, outliers were over 2 degrees more than the preoperatively scheduled alignment $[5,6]$. UKA was also

(c) The Author(s). 2021 Open Access This article is licensed under a Creative Commons Attribution 4.0 International License, which permits use, sharing, adaptation, distribution and reproduction in any medium or format, as long as you give appropriate credit to the original author(s) and the source, provide a link to the Creative Commons licence, and indicate if changes were made. The images or other third party material in this article are included in the article's Creative Commons licence, unless indicated otherwise in a credit line to the material. If material is not included in the article's Creative Commons licence and your intended use is not permitted by statutory regulation or exceeds the permitted use, you will need to obtain permission directly from the copyright holder. To view a copy of this licence, visit http://creativecommons.org/licenses/by/4.0/. 
associated with higher revision rate and lower survivorship [7-9].

Encouraged by improving clinical outcomes and survivorship due to use of more accurate placement of implants and optimal balance of soft-tissue, clinicians are putting into use more technologies, such as patient-specific cutting guides, computer navigation, and semi-customized patientspecific implants. Robotic-assisted unicompartmental knee arthroplasty (rUKA) aims to simplify procedures, maximize the accuracy of bone preparation and component positioning, reduce outliers, restore alignment as desired, and eventually improve clinical outcomes and prolong implant durability [10-13]. In the United States, 15 20\% of UKAs are performed under the assistance of robotic devices, and the rate is projected to reach over $37 \%$ in the next decade [14]. Furthermore, publications and patents related to raUKA have also been on the rise dramatically [15]. However, recent studies showed that improved precision failed to benefit function recovery, lower revision rate or protract implant survivorship [16-18]. Moreover, the problem of time- and cost-effectiveness of rUKA has yet to be resolved.

This review looked into the historical development and current application of rUKA and made some predictions about its future (Fig. 1).

\section{History of robotic-assisted surgery}

The rationales of robotic-assisted surgery mainly refer to preoperative plan, intraoperative guidance, and smart remote surgical technologies [19]. The first roboticassisted surgery was performed in neurosurgical biopsies dated back to 1985 , showing that the procedure could accomplish higher precision [20]. In 1989, Davies et al. published their results of transurethral resection of prostate [21]. Their study confirmed that using robotics to handle soft tissue in surgery was practicable. Since then, application of medical robotic-assisted technologies have been growing worldwide. The first robotic-assisted total hip arthroplasty (THA) was reportedly performed in 1992 [22]. A robotic device for performing TKA was first described in 1993 [23], and the Acrobot assistance system used for UKA was introduced initially in 2000. In 2006, Cobb reported that the robotic-assisted technology resulted in more accurate tibiofemoral alignment in UKA [6]. To date, with the rapid development of robotic assistance technology and increasing robotic-assisted procedures performed in UKA, robotic-assisted systems have also been used in patellofemoral and bicompartmental knee arthroplasty [24, 25].

\section{Platforms of the technology}

\section{Passive, active, and semi-active robotics}

According to autonomy of robotics, medical robotics fall into three types: passive, semi-active and active robotics [26]. Passive robotic systems provide recommendations for perioperative guidance of positioning, but surgical procedures have to be directly performed by the surgeon, without real robotic assistance. A typical example of passive systems is the OMNIBotics system. Active systems are capable of performing the surgery autonomously through pre-programmed algorithms and defined parameters for bone resection, and the surgeon simply controls the "shut-off" switch in emergency. A historical example is the RoboDoc system. Semi-active systems, for example the Mako system, are those in which surgical tasks are adjusted or constrained by the system, but the final execution of the operation still depends on the surgeon.

\section{Image-based vs. imageless}

A "pre-approved" execution plan before bone resection is essential for rUKA. The robotic-assisted systems are image-based or imageless, depending on preoperative and/or intraoperative mapping. Patients' anatomical structures must be registered via mapped points on the bone with a steering tool, so that the "robot" knows the space for the cutting tools, and a poor registration will lead to reduced accuracy.

With image-based systems, the registration is associated with patient-specific digital imaging data, usually using the ipsilateral hip, knee and ankle computed tomography (CT) scan. These imaging data are stored in the robotic system to accurately identify depth of bone resection, alignment and deformities that need to be corrected, and the boundaries of bone removal. The robot then carries out the surgeons' approved plan during procedure. Shortcomings of image-based system include added cost and radiation exposure [27]. Without image scan, imageless systems depend on the registration of the knee anatomy after surgical exposure by creating a virtual model. The surgical plan is carried out during the procedure and is updated according to the process of registration. This registration mainly depends on the accuracy of inputting data points, generally using computer navigation registration, which is easy to locate and label important landmarks. Advantages of imageless system include lower cost of the images, freedom from preoperative radiation exposure, and convenience to the patients. The possible disadvantages are lack of preoperative plan and inability to confirm the anatomic registration points.

\section{Closed vs. open platforms}

In terms of differences in compatibility, robotic systems are of two types: closed and open platforms. The closed one is designed for the implants of a single manufacturer, while the open one can adapt to the products of different companies. The open platform is designed to be used on the basis of the surgeon's preference or patients' requirement, but some unique features have vanished. For example, lack of design 


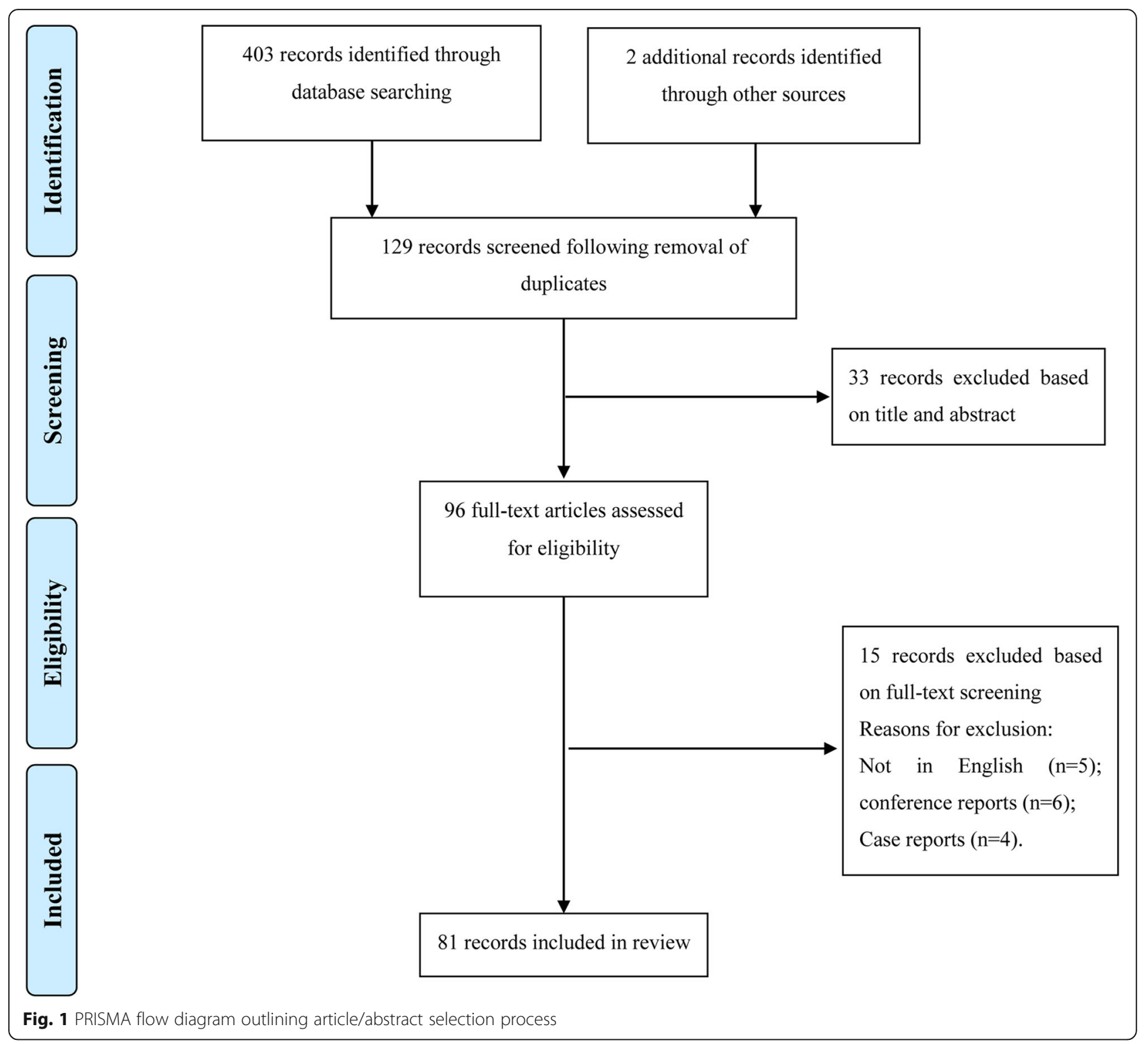

depth and biomechanical data does not allow optimization of component positioning. If coupled with an imageless system, some features and preoperative protocols are not applicable [28]. The ability of the closed platform to generate a visual image of the implant is attractive. Since prostheses need to be improved and software needs to be constantly upgraded, this "attractiveness" is both capital- and laborintensive. The clinical effectiveness of the two platforms is still controversial. With the operative system becoming increasingly user-friendly, surgeons are in a position to decide when to use the system as desired.

\section{Contemporary rUKA systems}

Most robotic-assisted systems are structurally comparable. The steps to a rUKA involve (1) establishing a specific model and designing a preoperative plan; (2) registering the model and plan based on the patient's anatomy during pre- or/and intraoperative period; and (3) implementing the preoperative plan in the patient under the guidance of robotic assistance. The most-used robotic-assisted systems include the Acrobot (Acrobot Ltd., Elstree, London, UK), Navio (Smith and Nephew, Pittsburgh, Pennsylvania, USA), and MAKO System (MAKO Surgical Corporation, Fort Lauderdale, Florida, USA) (Fig. 2). To date, no studies compared the accuracy or outcomes of one system against the others.

The Acrobot system is the first used robotic-assisted system in UKA and a prototype to modern haptic systems. It adopts an image-based closed semi-active robotic system, which restrains the motion to a predefined surgical region, and thereby enables the surgeon to safely cut affected knee bones to fit UKA 

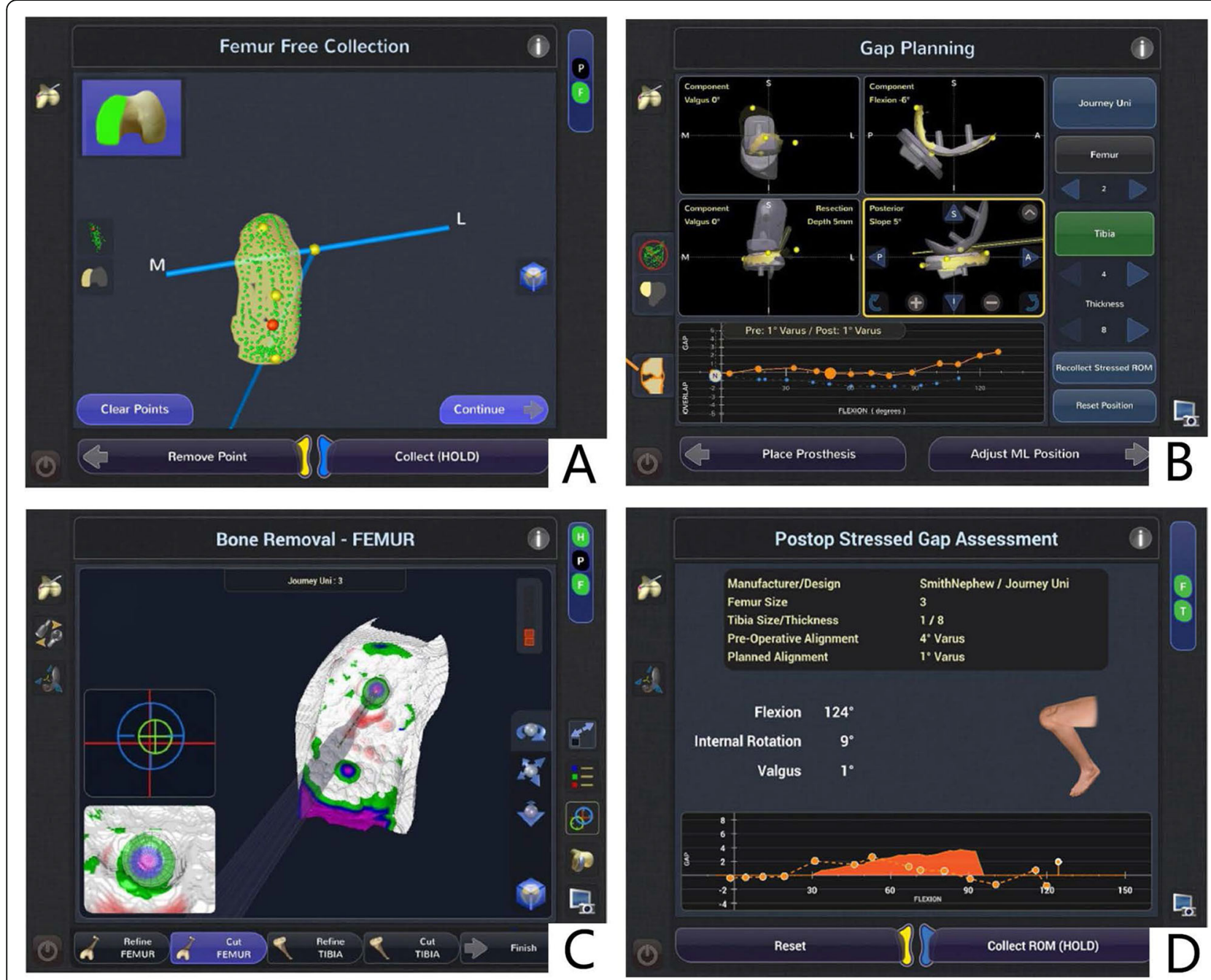

Fig. 2 A: Surface model formation of the femur during registration. B: Planning screen to show predicted gaps throughout a range of flexion. C: Screen guidance during bone reaming showing the remaining bone to be removed. D: Postoperative gap assessment under stress throughout a range of flexion [29]

prosthesis precisely. Intraoperatively, a non-invasive anatomical registration is applied to assist the surgeon when the drill is within the region on the basis of the preoperative plan. Meanwhile, it actively prevents the surgeon from cutting bone away from the defined area. The company merged to the Stanmore Implants Worldwide in 2010, and the latter released the Stanmore Sculptor Robotic Guidance Arm (RGA) System. Subsequently, MAKO Surgical obtained some confidential patents in 2013. The MAKO system is a more advanced haptically-guided one, and is currently being most commonly used for UKA, with a $20 \%$ market share for UKA in the United States [30]. MAKO system is also image-based. A preoperative CT scan is helpful in determining component size, position, and extent of bone resection. Intraoperatively, the haptic feedback system allows surgeons to safely resect bone within a pre-defined zone and prevent bone resection outside the volume [31]. The Navio system, produced by Blue Belt Technologies, now commercially available through Smith \& Nephew, is a hand-held, open-platform, image-free system. It employs optically-based navigation without imaging system, to minimize the risk of radiation exposure and related cost. As a semiautonomous system, it constantly monitors the surgeon's performance when he or she moves the handheld burr tool, as well as the location of the patient's lower limb, to ensure that only the planned volume bone is removed safely and in right orientation.

\section{Accuracy in rUKA}

UKA is a less forgiving procedure than TKA. Component malpositioning, malalignment, and ligament imbalance all contribute to a failed UKA [32, 33]. Multiple 
studies showed that, with robotic assistance, remarkable improvement has been made in accuracy of bone preparation, implant positioning, component alignment, and soft-tissue balance as compared with conventional techniques [10, 13, 34].

A meta-analysis assessed the accuracy of rUKA in 7 studies and indicated that robotic-assisted system in UKA could decrease the implantation errors [35]. Precision of bone preparation was evaluated in 25 cadaveric specimens on the Navio PFS system, and the final results showed that final implant position within a mean of 2 degrees rotational, and $1.3 \mathrm{~mm}$ translational errors of the planned target [36]. Lonner et al. compared postoperative tibial component position in 31 patients who received rUKAs with a matched group that underwent UKAs using manual instruments. The average root mean squared error (RMSE) used to evaluate postoperative component positioning was significantly improved (1.9 degrees vs. 3.1 degrees), with 2.6 times less variance in the robotic-assisted group $(p=0.02)$ [37]. One prospective, randomized controlled study by Bell et al. concluded that robotic-assisted surgery had lower RMSEs and achieved more accurate implantation of both tibial and femoral components on coronal, sagittal and axial planes $(p<0.01$ for all parameters) [38]. Compared with manual techniques, the robotic-assisted surgery is also associated with conservative tibial resection, maintenance of posterior femoral condylar offset ratio and restitution of joint-line height, theoretically allowing reinstatement of natural kinematics and normal range of motion [39-41].

Picard et al. conducted a study involving 65 Navioassisted medial UKA [42] and found that post-surgical mechanical axis alignment was within 1 degree of the intraoperative plan in $91 \%$ of cases. Batailler et al. [43] reported that rUKA was associated with a lower risk of postoperative limb alignment outliers. A follow-up lasting a mean time of 19.7 months showed that the rate of postoperative limb alignment outliers ( \pm 2 degrees) was substantially lower in the robotic-assisted group than in the conventional group with both lateral UKA (26\% vs. $61 \%, p=0.018)$ and medial UKA $(16 \%$ vs. $32 \%, p=$ 0.038). Plate and colleagues demonstrated that roboticassisted systems could help the surgeon precisely reproduce plans for soft-tissue balance [44]. The authors reported that ligament balance precision was up to 0.53 $\mathrm{mm}$ against the preoperative protocol, with approximately $83 \%$ of cases attaining balance within $1 \mathrm{~mm}$ of the plan through a full range of flexion.

However, not all studies supported robotic assistance. Hansen et al. compared 32 Mako-assisted UKAs and 32 conventional UKAs in a follow-up that lasted for at least 2 years [45]. They reported that the robotic techniques could improve the reproduction of the preoperative femoral axis $(P p=0.013)$, but no significant difference was found in tibial component position $(p=0.409)$. Another feasibility study by MacCallum et al. compared 87 rUKAs and 177 conventional UKAs in terms of tibial baseplate alignment [46]. The results showed that coronal baseplate positioning was more accurate with rUKAs $(2.6 \pm 1.5$ degrees vs. $3.9 \pm 2.4$ degrees, $p<0$. 0001), sagittal alignment was more accurate with conventional UKAs $(4.9 \pm 2.8$ degrees $v s .2 .4 \pm 1.6$ degrees, $p<0.0001)$. There was no difference in the percentage of implants within the safe zone between the two groups $(p=1.0)$. Bush et al. compared 128 consecutive medial manual UKAs performed by an experienced surgeon with published rUKAs in tibial component alignment [47]. The results showed that the percentage of preoperative target and RMSE for tibial component alignment was higher $(66 \%$ vs. $58 \%$ / 1.48 degrees vs. 1.8 to 5 degrees) (Table 1).

\section{Clinical outcomes and implant survivorship in rUKA}

A meta-analysis involving 11 studies examined the clinical outcomes of rUKA and those of conventional UKA and found that rUKA could reduce the complication rate and improve knee excursion [48]. One prospective cohort study compared the early clinical outcomes in 146 patients who received medial UKAs split evenly to using either conventional devices or robotic-arm assisted devices. A less than 90-day follow-up showed that rUKA was associated with alleviated postoperative pain, reduced opiate analgesia requirements, shorter time to straight leg raise and hospital discharge, decreased physiotherapy sessions, and increased maximum knee flexion at discharge $(p<0.001$ for all parameters) in comparison with those receiving the conventional UKAs. Meanwhile, no difference was found in the occurrence of postoperative complications between the two groups [49]. Motesharei et al. conducted a prospective randomized controlled trial regarding postoperative function in 70 patients (31 receiving rUKA, and 39 receiving manual UKA) and compared them with healthy participants. Their study showed that the rUKA group accomplished better outcomes in term of kinematics from foot-strike to mid-stance than the conventional group during the postoperative 1 year [50]. Canetti et al. reported that rUKAs could achieve quicker return to sports than conventional UKAs $(4.2 \pm 1.8$ months $v s$. $10.5 \pm 6.7$ months, $p<0.01)$ at pre-symptomatic levels [51].

As to short-term results, a retrospective study followed up 128 patients from five institutions for an average of 2.3 years and found that survivorship rate of the Navio rUKA was 99.2\% [29]. Pearle and colleagues conducted a prospective multi-center study on 1135 rUKAs performed in six separate institutions and a follow-up lasting a mean time of 2.5-year [52] found that 11 knees were revised, resulting in an overall survivorship of 
Table 1 Results of accuracy in robotic-assisted UKA

\begin{tabular}{|c|c|c|c|}
\hline Studies & System & $\begin{array}{l}\text { Level of } \\
\text { evidence }\end{array}$ & Main findings \\
\hline $\begin{array}{l}\text { Kwon et al. [62] } \\
2019\end{array}$ & Mako & III & $\begin{array}{l}\text { During passive flexion, the mean values both before and after insertion of the implant were lower in } \\
\text { goniometer group than in robot group. }\end{array}$ \\
\hline $\begin{array}{l}\text { Batailler et al. [40] } \\
2019\end{array}$ & Navio & III & $\begin{array}{l}\text { rUKA has a lower rate of postoperative limb alignment outliers both in lateral and medial UKA, compared } \\
\text { to conventional technique. }\end{array}$ \\
\hline $\begin{array}{l}\text { Iñiguez et al. [63] } \\
2019\end{array}$ & Navio & IV & MDFA and MPTA were significant difference with median of $1.07^{\circ} \mathrm{vs} .0 .12^{\circ}$ and $1.28^{\circ} \mathrm{vs} .1 .3^{\circ}$ respectively \\
\hline $\begin{array}{l}\text { Deese et al. [12] } \\
2018\end{array}$ & Mako & III & Robotic-arm assisted surgery is reported to improve the accuracy of implant placement. \\
\hline $\begin{array}{l}\text { Motesharei et al. } \\
\text { [50] } 2018\end{array}$ & Mako & ॥ & $\begin{array}{l}\text { rUKA achieved a higher knee excursion }\left(18.0^{\circ} \pm 4.9^{\circ}\right) \text { compared to the manual group }\left(15.7^{\circ} \pm 4.1^{\circ}\right) \text {, leading } \\
\text { to not only better implant alignment but also some kinematic benefits to the user during walk. }\end{array}$ \\
\hline $\begin{array}{l}\text { Khare et al. [64] } \\
2018\end{array}$ & Navio & IV & $\begin{array}{l}\text { rUKA system offers significant improvement in the femoral and tibial implant placement compared with } \\
\text { conventional UKA system. }\end{array}$ \\
\hline $\begin{array}{l}\text { kayani et al. [49] } \\
2018\end{array}$ & Mako & III & rUKA improved accuracy of femoral $(p<0.001)$ and tibial $(p<0.001)$ implant positioning. \\
\hline $\begin{array}{l}\text { Gaudiani et al. [39] } \\
2017\end{array}$ & Mako & III & Posterior tibial slope was lower after rUKA compared to the native knee $\left(4.91^{\circ} \mathrm{vs} .2 .28^{\circ}, p<0.0001\right)$ \\
\hline $\begin{array}{l}\text { Herry et al. [40] } \\
2017\end{array}$ & Navio & III & Restitution of joint-line height was improved with robotic-assisted group compared to the control group. \\
\hline $\begin{array}{l}\text { MacCallum et al. } \\
\text { [46] } 2016\end{array}$ & Mako & III & Tibial coronal positioning was more accurate with robotic-arm-assisted $\left(2.6^{\circ} \pm 1.5^{\circ} \mathrm{vs} .3 .9^{\circ} \pm 2.4^{\circ}, p<0.0001\right)$. \\
\hline $\begin{array}{l}\text { Bell et al. [38] } \\
2016\end{array}$ & Mako & $\|$ & $\begin{array}{l}\text { MAKO-assisted UKA lead to improved accuracy of femoral and tibial component positioning, except for } \\
\text { tibial coronal position. }\end{array}$ \\
\hline $\begin{array}{l}\text { Lonner et al. [36] } \\
2015\end{array}$ & Navio & IV & $\begin{array}{l}\text { The image-free robotic devices achieved accurate implementation of the surgical plan with small errors in } \\
\text { implant placement. }\end{array}$ \\
\hline $\begin{array}{l}\text { Mofidi et al. [31] } \\
2014\end{array}$ & Mako & III & $\begin{array}{l}\text { Robotic-assisted medial UKA results in an average difference of } 2.2^{\circ} \pm 1.7^{\circ} \text { to } 3.6^{\circ} \pm 3.3^{\circ} \text {, inaccuracy may be } \\
\text { attributed to suboptimal cementing technique. }\end{array}$ \\
\hline $\begin{array}{l}\text { Citak et al. [65] } \\
2013\end{array}$ & Mako & IV & $\begin{array}{l}\text { UKA was more precise using a semi-active robotic system with dynamic bone tracking technology com } \\
\text { pared to the manual technique. }\end{array}$ \\
\hline $\begin{array}{l}\text { Plate et al. [44] } \\
2013\end{array}$ & Mako & III & rUKA allows ligament balancing with an accuracy of up to $0.53 \mathrm{~mm}$, being $1 \mathrm{~mm}$ in $83 \%$ of cases. \\
\hline $\begin{array}{l}\text { Smith et al. [31] } \\
2013\end{array}$ & Navio & IV & $\begin{array}{l}\text { The freehand sculpting tool was shown to produce accurate implant placement with small errors which } \\
\text { are comparable to those reported by other robotic assistive devices on the market for UKA. }\end{array}$ \\
\hline $\begin{array}{l}\text { Karia et al. [66] } \\
2013\end{array}$ & Mako & IV & $\begin{array}{l}\text { Robotic assistance enabled surgeons to achieve better precision and accuracy when positioning UKA } \\
\text { components irrespective of their experience. }\end{array}$ \\
\hline $\begin{array}{l}\text { Becker et al. [67] } \\
2012\end{array}$ & KUKA & IV & The natural knee stability in antero-posterior translation and rotation can be preserved in rUKA. \\
\hline $\begin{array}{l}\text { Dunbar et al. [68] } \\
2012\end{array}$ & Mako & III & Implant placement errors were comparable between tactile robotics and rigid stereotactic fixation. \\
\hline $\begin{array}{l}\text { Pearle et al. [69] } \\
2010\end{array}$ & Mako & III & $\begin{array}{l}\text { Haptic guidance in combination with a navigation module allows the planned and intraoperative tibio- } \\
\text { femoral angle was within } 1^{\circ} \text { and postoperative long leg axis radiographs were within } 1.6^{\circ} \text { in UKA. }\end{array}$ \\
\hline $\begin{array}{l}\text { Lonner et al. [37] } \\
2010\end{array}$ & Mako & III & $\begin{array}{l}\text { Tibial component alignment is more accurate and less variable using robotic arm assistance than manual } \\
\text { instrumentation. }\end{array}$ \\
\hline Cobb et al. [6] 2006 & Acrobot & $\|$ & $\begin{array}{l}\text { All the Acrobot cases have limb alignment in the coronal plane within } 2^{\circ} \text { of the planned position, while } \\
\text { only } 40 \% \text { of the conventional group achieved this level of accuracy. }\end{array}$ \\
\hline $\begin{array}{l}\text { Rodriguez et al. [70] } \\
2005\end{array}$ & Acrobot & ॥ & $\begin{array}{l}\text { All of robotic cases were implanted with tibio-femoral alignment on the coronal plane within } \pm 2^{\circ} \text { of the } \\
\text { planned position. }\end{array}$ \\
\hline
\end{tabular}

98.8\%. The short-term survivorship of rUKA was marginally better that those reported by other large-sized follow-up studies about conventional UKA [53]. Kleeblad et al. followed up 432 rUKAs from four institutions in a follow-up lasting5.7-year on average and revealed a survivorship rate of $97 \%$ [54]. A recent systematic review involving 38 studies exhibited that the survivorship rate was $96 \%$, as evidenced by a 6 -year follow-up [55] . This survival rate was lower than that of the TKA survivorship in cohort $(97.7 \%)$ as well as registry (96.8\%) studies at mid-term follow-up [56]. These recent data showed that further long-term studies are warranted to know 
whether rUKA can achieve better clinical outcomes than conventional UKA, or whether the improved robotic accuracy will exerts positive influence on implant survivorship (Tables 2 and 3).

\section{Potential downsides of robotic-assisted UKA}

It is worth mentioning that rUKA is not without limitations. First, the greatest barrier for robots to go into the operating room may be its staggering initial cost. Additionally, it also imposes maintenance cost, cost of disposable elements, and education cost on surgeons and other staff. Systems that require preoperative CT scans incur additional cost of imaging examination [27]. Moschetti et al. showed that rUKA was more costeffective than manual technique, only when the annual cases exceeded 94 and the failure rate was lower than $1.2 \%$ over a period of 2 years [57]. Second, advanced and novel technologies should not increase operative time at the expense of the desired outcomes. The operative time may be longer, especially when the learning curve is involved, by an average margin of $20 \mathrm{~min}$ [58]. However, a systematic review revealed that there was no learning curve involved for accuracy and operative time [59]. Third, current robotic systems are used to carry out a specific plan on the basis of the accurate registration data. Therefore, intraoperative insertion of percutaneous pins is required for optical tracking arrays. The intraosseous placement of pins can theoretically cause iatrogenic complications, including pin-related periprosthetic fracture, neurovascular laceration, pin site infection or broken pins. Fourth, these systems are still unable to make creative or original decisions, or unilaterally decide how to change the surgical plan during the procedure if a new variable presents itself (e.g. ruptured MCL, fracture, deficient ACL). In addition, these systems will follow the designed plan and make pre-determined cuts without considering what they will cut. Therefore, the surgeon must take care of the soft tissues, or the tissues will be damaged in the planned path. Finally, $51 \%$ of papers concerning rUKA were probably industry-funded or written by authors with financial conflicts of interest, and $24 \%$ of these papers were published in journals with low impact factors or even not indexed by the Journal Citations Report. Therefore, in order to obtain more objective and accurate data and conclusions based on these papers, readers should be fully aware of possible conflicts of interests [60].

\section{Future robotic innovations}

Current design concerning rUKA focuses on reducing outliers and increasing accuracy in radiographic outcomes. It is demonstrated that decreased revision rates and improved clinical outcomes can be accomplished by using robotic-assisted technologies. Further research effort should be directed at how to simplify the procedure and shorten the learning curve and operative time. Future innovations will likely continue to improve the preoperative plan, intraoperative sensors, and roboticallycontrolled instruments. About $80 \%$ of rUKA were performed in teaching hospitals and the trend would intensify in future [61]. This suggested that residents and fellows should learn to use robotic-assisted technologies

Table 2 Outcomes in robotic-assisted UKA

\begin{tabular}{|c|c|c|c|}
\hline Studies & System & $\begin{array}{l}\text { Level of } \\
\text { evidence }\end{array}$ & Main findings \\
\hline $\begin{array}{l}\text { Kayani et al. [49] } \\
2019\end{array}$ & Mako & III & $\begin{array}{l}\text { rUKA was associated with reduced postoperative pain, decreased opiate analgesia requirements, } \\
\text { improved early functional rehabilitation, and shorter time to hospital discharge compared with } \\
\text { conventional UKA. }\end{array}$ \\
\hline $\begin{array}{l}\text { Wong et al. [16] } \\
2019\end{array}$ & Mako & III & $\begin{array}{l}\text { rUKA was not superior to conventional UKA in terms of functional scores, while was associated with } \\
\text { longer operative time and cost and lower survivorship at short-term follow-up of } 2 \text { years. }\end{array}$ \\
\hline $\begin{array}{l}\text { Dretakis et al. } \\
\text { [10] } 2019\end{array}$ & Mako & III & rUKA significantly improved range of motion and coronal plane alignment. \\
\hline $\begin{array}{l}\text { Gilmour et al. } \\
\text { [13] } 2018\end{array}$ & Mako & $\|$ & More active patients may benefit from rUKA. \\
\hline $\begin{array}{l}\text { Canetti et al. [51] } \\
2018\end{array}$ & Navio & III & $\begin{array}{l}\text { Robotic-assisted lateral UKA reduced the time to return to sports at pre-symptomatic levels when com- } \\
\text { pared with conventional surgical technique }(4.2 \pm 1.8 \text { months vs. } 10.5 \pm 6.7 \text { months), with a comparable } \\
\text { rate of return to sports ( } 100 \% \text { vs. } 94 \%) \text {. }\end{array}$ \\
\hline $\begin{array}{l}\text { Blyth et al. [36] } \\
2017\end{array}$ & Mako & $\|$ & $\begin{array}{l}\text { Robotic arm-assisted surgery resulted in lower median pain scores than those observed in the manual } \\
\text { UKA group from the first postoperative day to week } 8 \text { postoperatively. }\end{array}$ \\
\hline $\begin{array}{l}\text { Marcovigi et al. } \\
\text { [71] } 2017\end{array}$ & Mako & III & $\begin{array}{l}\text { rUKA provided an improvement in terms of both clinical and technical results, and a low risk of } \\
\text { postoperative complications. }\end{array}$ \\
\hline $\begin{array}{l}\text { Plate et al. [49] } \\
2017\end{array}$ & Mako & IV & Obesity had no effect on rUKA at a minimum follow-up of 24 months. \\
\hline $\begin{array}{l}\text { Hansen et al. [45] } \\
2014\end{array}$ & Mako & III & $\begin{array}{l}\text { Robotic guidance did little to change clinical or radiographic outcomes, and average operative time was } \\
\text { longer with an average of } 20 \mathrm{~min}(p=0.010) \text {. }\end{array}$ \\
\hline
\end{tabular}


Table 3 Survivorship in robotic-assisted UKA

\begin{tabular}{llll}
\hline Study & System & Level of evidence & Survivorship \\
\hline Burger et al. [72] 2020 & Mako & III & $97.8 \%$ \\
Battenberg et al. [29] 2019 & Navio & III & $99.2 \%$ \\
Wong et al. [16] 2019 & Mako & III & $93.2 \%$ \\
Zambianchi et al. [73] 2019 & Mako & IV & $99.0 \%$ \\
Batailler et al. [43] 2018 & Navio & III & $95.0 \%$ \\
Kleeblad et al. [54] 2018 & Mako & III & $97.0 \%$ \\
\hline
\end{tabular}

earlier whenever possible during their medical education training.

\section{Conclusion}

To date, rUKA has been demonstrated to increase accuracy and decreased outliers at the expense of increased operative time and medical cost and some short- and mid-term evidence supported its ability to improve clinical outcomes. In the future, robotics will become a valuable supplement for surgeons to simplify the operative process and make individual-specific plan. Although, more data are need to reach a definitive conclusion about the pros and cons of robotic assistance, one thing is clear: robotic-assisted operation is now being increasingly used in medical practice.

\section{Abbreviations}

CT: Computed tomography; rUKA: Robotic-assisted unicompartmental knee arthroplasty; RMSE: Root mean squared error; THA: Total hip arthroplasty; TKA: Total knee arthroplasty; UKA: Unicompartmental knee arthroplasty

\section{Acknowledgements}

Not applicable.

\section{Authors' contributions}

Conceptualization: Pei Liu, Wan-shou Guo. Data curation: Pei Liu, Fei-fan Lu, Guo-jie Liu, Xiao-hong Mu. Data analysis: Wei-guo Wang, Pei Liu, Guo-jie Liu. Investigation: Qi-dong Zhang, Guo-jie Liu, Yong-qiang Sun, Wei-guo Wang. Methodology: Pei Liu, Qi-dong Zhang, Yong-qiang Sun, Wei-guo Wang. Project administration: Pei Liu, Qi-dong Zhang, Guo-jie Liu, Wan-shou Guo. Validation: Wei-guo Wang, Wan-shou Guo. Preparation of original draft: Pei Liu. Writing, review and revision: Pei Liu, Wan-shou Guo. The author(s) read and approved the final manuscript

\section{Funding}

This work was supported by grants from the National Natural Science Foundation of China (No. 81972130), Beijing Municipal Science and Technology Commission (No. Z171100001017209), and National Key Research and Development Program of China (No. 2017YFC0108102).

\section{Availability of data and materials}

The datasets used and/or analyzed in the current study are available from the corresponding author on reasonable request.

\section{Ethics approval and consent to participate}

Not applicable.

\section{Consent for publication}

All patients provided consents to participate in this study, as per our institution's standards as stated in the research consent forms, which specifies that the research information obtained may be used for publication.

\section{Competing interests}

The authors have no conflicts of interest or competing interests in the study implementation, publication or data interpretation.

\section{Author details \\ ${ }^{1}$ Department of Adult Joint Reconstruction, Henan Luoyang Orthopaedic Hospital (Henan Provincial Orthopaedic Hospital), Yongping Road, Zhengdong New District, Zhengzhou, China. ${ }^{2}$ China-Japan Friendship School of Clinical Medicine, Peking University, Yinghuadong Road, Chaoyang District, Beijing, China. ${ }^{3}$ Department Orthopedics 4, Beijing University of Chinese Medicine, Dongzhimen Hospital, Beijing, China. ${ }^{4}$ Department of Orthopaedic Surgery, Beijing Key Lab Immune-Mediated Inflammatory Diseases, China-Japan Friendship Hospital, No. 2, Yinghuadong Road, Chaoyang District, Beijing 100029, China.}

Received: 6 August 2020 Accepted: 21 January 2021

Published online: 02 May 2021

\section{References}

1. Chalmers BP, Mehrotra KG, Sierra RJ, Pagnano MW, Taunton MJ, Abdel MP. Reliable outcomes and survivorship of unicompartmental knee arthroplasty for isolated compartment osteonecrosis. Bone Joint J. 2018;100-B:450-4. https://doi.org/10.1302/0301-620X.100B4.BJJ-2017-1041.R2.

2. Liddle AD, Pandit $H$, Judge A, Murray DW. Patient-reported outcomes after total and unicompartmental knee arthroplasty: a study of 14,076 matched patients from the National Joint Registry for England and Wales. Bone Joint J. 2015;97-B:793-801. https://doi.org/10.1302/0301-620X.97B6.35155.

3. Jenny JY, Boeri C. Unicompartmental knee prosthesis implantation with a non-image-based navigation system: rationale, technique, case-control comparative study with a conventional instrumented implantation. Knee Surg Sports Traumatol Arthrosc. 2003;11:40-5. https://doi.org/10.1007/ s00167-002-0333-8.

4. Fisher DA, Watts M, Davis KE. Implant position in knee surgery: a comparison of minimally invasive, open unicompartmental, and total knee arthroplasty. J Arthroplast. 2003;18:2-8.

5. Keene G, Simpson D, Kalairajah Y. Limb alignment in computer-assisted minimally-invasive unicompartmental knee replacement. J Bone Joint Surg (Br). 2006;88:44-8. https://doi.org/10.1302/0301-620X.88B1.16266.

6. Cobb J, Henckel J, Gomes P, Harris S, Jakopec M, Rodriguez F, et al. Handson robotic unicompartmental knee replacement: a prospective, randomised controlled study of the acrobot system. J Bone Joint Surg (Br). 2006;88:18897. https://doi.org/10.1302/0301-620X.88B2.17220.

7. Liddle AD, Judge A, Pandit H, Murray DW. Adverse outcomes after total and unicompartmental knee replacement in 101,330 matched patients: a study of data from the National Joint Registry for England and Wales. Lancet. 2014:384:1437-45, https://doi.org/10.1016/S0140-6736(14)60419-0.

8. Labek G, Sekyra K, Pawelka W, Janda W, Stockl B. Outcome and reproducibility of data concerning the Oxford unicompartmental knee arthroplasty: a structured literature review including arthroplasty registry data. Acta Orthop. 2011:82:131-5. https://doi.org/10.3109/17453674.2011. 566134

9. Emerson RJ, Higgins LL. Unicompartmental knee arthroplasty with the oxford prosthesis in patients with medial compartment arthritis. J Bone Joint Surg Am. 2008;90:118-22. https://doi.org/10.2106/JBJS.F.00739.

10. Dretakis K, Igoumenou VG. Outcomes of robotic-arm-assisted medial unicompartmental knee arthroplasty: minimum 3-year follow-up. Eur J Orthop Surg Traumatol. 2019. https://doi.org/10.1007/s00590-019-02424-4.

11. Cool CL, Needham KA, Khlopas A, Mont MA. Revision analysis of robotic arm-assisted and manual unicompartmental knee arthroplasty. J Arthroplast. 2019;34:926-31. https://doi.org/10.1016/j.arth.2019.01.018.

12. Deese JM, Gratto-Cox G, Carter DA, Sasser TJ, Brown KL. Patient reported and clinical outcomes of robotic-arm assisted unicondylar knee arthroplasty: minimum two year follow-up. J Orthop. 2018;15:847-53. https://doi.org/10. 1016/j.jor.2018.08.018.

13. Gilmour A, MacLean AD, Rowe PJ, Banger MS, Donnelly I, Jones BG, et al. Robotic-arm-assisted vs conventional unicompartmental knee arthroplasty. The 2-year clinical outcomes of a randomized controlled trial. J Arthroplast. 2018;33:S109-15. https://doi.org/10.1016/j.arth.2018.02.050.

14. Lonner JH, Moretti VM. The evolution of image-free robotic assistance in Unicompartmental knee Arthroplasty. Am J Orthop (Belle Mead NJ). 2016;45: 249-54. 
15. Dalton DM, Burke TP, Kelly EG, Curtin PD. Quantitative analysis of technological innovation in knee arthroplasty: using patent and publication metrics to identify developments and trends. J Arthroplast. 2016;31:1366-72. https://doi.org/10.1016/j.arth.2015.12.031.

16. Wong J, Murtaugh T, Lakra A, Cooper HJ, Shah RP, Geller JA. Roboticassisted unicompartmental knee replacement offers no early advantage over conventional unicompartmental knee replacement. Knee Surg Sports Traumatol Arthrosc. 2019. https://doi.org/10.1007/s00167-019-05386-6.

17. van der List JP, Chawla H, Joskowicz L, Pearle AD. Current state of computer navigation and robotics in unicompartmental and total knee arthroplasty: a systematic review with meta-analysis. Knee Surg Sports Traumatol Arthrosc. 2016;24:3482-95. https://doi.org/10.1007/s00167-016-4305-9.

18. Song EKNM, Lee SH, Na BR, Seon JK. Comparison of outcome and survival after unicompartmental knee arthroplasty between navigation and conventional techniques with an average 9-year follow-up. J Arthroplast. 2016;31:395-400. https://doi.org/10.1016/j.arth.2015.09.012.

19. Moustris GP, Hiridis SC, Deliparaschos KM, Konstantinidis KM. Evolution of autonomous and semi-autonomous robotic surgical systems: a review of the literature. Int J Med Robot. 2011;7:375-92. https:/doi.org/10.1002/rcs.408.

20. Kwoh YS, Hou J, Jonckheere EA, Hayati S. A robot with improved absolute positioning accuracy for $\mathrm{CT}$ guided stereotactic brain surgery. IEEE Trans Biomed Eng. 1988;35:153-60. https://doi.org/10.1109/10.1354

21. Davies BL, Hibberd RD, Coptcoat MJ, Wickham JE. A surgeon robot prostatectomy--a laboratory evaluation. J Med Eng Technol. 1989;13:273-7.

22. Spencer EH. The ROBODOC clinical trial: a robotic assistant for total hip arthroplasty. Orthop Nurs. 1996;15:9-14.

23. Matsen FR, Garbini JL, Sidles JA, Pratt B, Baumgarten D, Kaiura R. Robotic assistance in orthopaedic surgery. A proof of principle using distal femoral arthroplasty. Clin Orthop Relat Res. 1993:178-86.

24. Tamam C, Plate JF, Augart M, Poehling GG, Jinnah RH. Retrospective clinical and radiological outcomes after robotic assisted bicompartmental knee arthroplasty. Adv Orthop. 2015;2015:747309. https://doi.org/10.1155/2015/747309.

25. Watanabe T, Abbasi AZ, Conditt MA, Christopher J, Kreuzer S, Otto JK, et al. In vivo kinematics of a robot-assisted uni- and multi-compartmental knee arthroplasty. J Orthop Sci. 2014;19:552-7. https://doi.org/10.1007/s00776014-0578-3.

26. Netravali NA, Shen F, Park Y, Bargar WL. A perspective on robotic assistance for knee arthroplasty. Adv Orthop. 2013;2013:970703. https://doi.org/10. 1155/2013/970703

27. Ponzio DY, Lonner JH. Preoperative mapping in unicompartmental knee arthroplasty using computed tomography scans is associated with radiation exposure and carries high cost. J Arthroplast. 2015;30:964-7. https://doi.org/ 10.1016/j.arth.2014.10.039.

28. Banerjee S, Cherian JJ, Elmallah RK, Pierce TP, Jauregui JJ, Mont MA. Robotassisted total hip arthroplasty. Expert Rev Med Devices. 2016;13:47-56. https://doi.org/10.1586/17434440.2016.1124018.

29. Battenberg AK, Netravali NA, Lonner JH. A novel handheld robotic-assisted system for unicompartmental knee arthroplasty: surgical technique and early survivorship. J Robot Surg. 2019. https:/doi.org/10.1007/s11701-018-00907-w.

30. van der List JP, Chawla H, Pearle AD. Robotic-assisted knee arthroplasty: an overview. Am J Orthop (Belle Mead NJ). 2016;45:202-11.

31. Lang JE, Mannava S, Floyd AJ, Goddard MS, Smith BP, Mofidi A, et al. Robotic systems in orthopaedic surgery. J Bone Joint Surg (Br). 2011;93: 1296-9. https://doi.org/10.1302/0301-620X.93B10.27418.

32. Epinette JA, Brunschweiler B, Mertl P, Mole D, Cazenave A. Unicompartmental knee arthroplasty modes of failure: wear is not the main reason for failure: a multicentre study of 418 failed knees. Orthop Traumatol Surg Res. 2012;98:S124-30. https://doi.org/10.1016/j.otsr.2012.07.002.

33. van der List JP, Zuiderbaan HA, Pearle AD. Why do medial unicompartmental knee arthroplasties fail today? J Arthroplast. 2016;31: 1016-21. https://doi.org/10.1016/j.arth.2015.11.030

34. Blyth M, Anthony I, Rowe P, Banger MS, MacLean A, Jones B. Robotic arm-assisted versus conventional unicompartmental knee arthroplasty: exploratory secondary analysis of a randomised controlled trial. Bone Joint Res. 2017;6:631-9. https://doi.org/10.1302/2046-3758.611.BJR2017-0060.R1

35. Fu J, Wang Y, Li X, Yu B, Ni M, Chai W, et al. Robot-assisted vs conventional unicompartmental knee arthroplasty: Systematic review and meta-analysis. Orthopade. 2018;47:1009-17. https://doi.org/10.1007/s00132-018-3604-X.

36. Lonner JH, Smith JR, Picard F, Hamlin B, Rowe PJ, Riches PE. High degree of accuracy of a novel image-free handheld robot for unicondylar knee arthroplasty in a cadaveric study. Clin Orthop Relat Res. 2015;473:206-12. https://doi.org/10.1007/s11999-014-3764-x.

37. Lonner JH, John TK, Conditt MA. Robotic arm-assisted UKA improves tibial component alignment: a pilot study. Clin Orthop Relat Res. 2010;468:141-6. https://doi.org/10.1007/s11999-009-0977-5.

38. Bell SW, Anthony I, Jones B, MacLean A, Rowe P, Blyth M. Improved accuracy of component positioning with robotic-assisted unicompartmental knee arthroplasty: data from a prospective, randomized controlled study. J Bone Joint Surg Am. 2016;98:627-35. https://doi.org/10.2106/JBJS.15.00664.

39. Gaudiani MA, Nwachukwu BU, Baviskar JV, Sharma M, Ranawat AS. Optimization of sagittal and coronal planes with robotic-assisted unicompartmental knee arthroplasty. Knee. 2017;24:837-43. https://doi.org/10.1016/j.knee.2017.05.002.

40. Herry $Y$, Batailler C, Lording T, Servien E, Neyret P, Lustig S. Improved jointline restitution in unicompartmental knee arthroplasty using a roboticassisted surgical technique. Int Orthop. 2017;41:2265-71. https://doi.org/10. 1007/s00264-017-3633-9

41. Ponzio DY, Lonner JH. Robotic technology produces more conservative tibial resection than conventional techniques in UKA. Am J Orthop (Belle Mead NJ). 2016;45:E465-8.

42. Picard F, Gregori A, Bellemans J. Handheld robot-assisted unicondylar knee arthroplasty: a clinical review. 14Th Annual Meeting of the International Society for Computer Assisted Orthopaedic Surgery. 2014;Italy; 2014

43. Batailler C, White N, Ranaldi FM, Neyret P, Servien E, Lustig S. Improved implant position and lower revision rate with robotic-assisted unicompartmental knee arthroplasty. Knee Surg Sports Traumatol Arthrosc. 2019;27:1232-40. https://doi.org/10.1007/s00167-018-5081-5.

44. Plate JF, Mofidi A, Mannava S, Smith BP, Lang JE, Poehling GG, et al. Achieving accurate ligament balancing using robotic-assisted unicompartmental knee arthroplasty. Adv Orthop. 2013;2013:837167. https://doi.org/10.1155/2013/837167.

45. Hansen DC, Kusuma SK, Palmer RM, Harris KB. Robotic guidance does not improve component position or short-term outcome in medial unicompartmental knee arthroplasty. J Arthroplast. 2014:29:1784-9. https:// doi.org/10.1016/j.arth.2014.04.012.

46. MacCallum KP, Danoff JR, Geller JA. Tibial baseplate positioning in roboticassisted and conventional unicompartmental knee arthroplasty. Eur J Orthop Surg Traumatol. 2016;26:93-8. https://doi.org/10.1007/s00590-015-1708-0.

47. Bush AN, Ziemba-Davis M, Deckard ER, Meneghini RM. An experienced surgeon can meet or exceed robotic accuracy in manual unicompartmental knee arthroplasty. J Bone Joint Surg Am. 2019:1479-84. https://doi.org/10. 2106/JBJS.18.00906.

48. Zhang F, Li H, Ba Z, Bo C, Li K. Robotic arm-assisted vs conventional unicompartmental knee arthroplasty: A meta-analysis of the effects on clinical outcomes. Medicine (Baltimore). 2019;98:e16968. https://doi.org/10. 1097/MD.0000000000016968.

49. Kayani B, Konan S, Tahmassebi J, Rowan FE, Haddad FS. An assessment of early functional rehabilitation and hospital discharge in conventional versus robotic-arm assisted unicompartmental knee arthroplasty. Bone Joint J. 2019;101-B:24. https://doi.org/10.1302/0301-620X.101B1.

50. Motesharei A, Rowe P, Blyth M, Jones B, Maclean A. A comparison of gait one year post operation in an RCT of robotic UKA versus traditional Oxford UKA. Gait Posture. 2018:62:41-5. https://doi.org/10.1016/j.gaitpost.2018.02.029.

51. Canetti R, Batailler C, Bankhead C, Neyret P, Servien E, Lustig S. Faster return to sport after robotic-assisted lateral unicompartmental knee arthroplasty: a comparative study. Arch Orthop Trauma Surg. 2018;138:1765-71. https://doi. org/10.1007/s00402-018-3042-6.

52. Pearle AD, van der List JP, Lee L, Coon TM, Borus TA, Roche MW. Survivorship and patient satisfaction of robotic-assisted medial unicompartmental knee arthroplasty at a minimum two-year follow-up. Knee. 2017;24:419-28. https://doi.org/10.1016/j.knee.2016.12.001.

53. Evans JT, Walker RW, Evans JP, Blom AW, Sayers A, Whitehouse MR. How long does a knee replacement last? A systematic review and meta-analysis of case series and national registry reports with more than 15 years of follow-up. Lancet. 2019:393:655-63. https://doi.org/10.1016/S0140-6736(18)32531-5.

54. Kleeblad LJ, Borus TA, Coon TM, Dounchis J, Nguyen JT, Pearle AD. Midterm survivorship and patient satisfaction of robotic-arm-assisted medial unicompartmental knee arthroplasty: a multicenter study. J Arthroplast. 2018;33:1719-26. https://doi.org/10.1016/j.arth.2018.01.036.

55. Robinson PG, Clement ND, Hamilton D, Blyth M, Haddad FS, Patton JT. A systematic review of robotic-assisted unicompartmental knee arthroplasty. Bone Joint J. 2019;101-B:838-47. https://doi.org/10.1302/0301-620X.101B7. BJJ-2018-1317.R1. 
56. Chawla $H$, van der List JP, Christ AB, Sobrero MR, Zuiderbaan HA, Pearle AD. Annual revision rates of partial versus total knee arthroplasty: a comparative meta-analysis. Knee. 2017;24:179-90. https://doi.org/10.1016/j.knee.2016.11.006.

57. Moschetti WE, Konopka JF, Rubash HE, Genuario JW. Can robot-assisted unicompartmental knee arthroplasty be cost-effective? A markov decision analysis. J Arthroplast. 2016;31:759-65. https://doi.org/10.1016/j. arth.2015.10.018.

58. Weber P, Crispin A, Schmidutz F, Utzschneider S, Pietschmann MF, Jansson $V$, et al. Improved accuracy in computer-assisted unicondylar knee arthroplasty: a meta-analysis. Knee Surg Sports Traumatol Arthrosc. 2013;21: 2453-61. https://doi.org/10.1007/s00167-013-2370-x.

59. Clement ND, Al-Zibari M, Afzal I, Deehan DJ, Kader D. A systematic review of imageless hand-held robotic-assisted knee arthroplasty: learning curve, accuracy, functional outcome and survivorship. EFORT Open Rev. 2020;5: 319-26. https://doi.org/10.1302/2058-5241.5.190065.

60. Cavinatto L, Bronson MJ, Chen DD, Moucha CS. Robotic-assisted versus standard unicompartmental knee arthroplasty-evaluation of manuscript conflict of interests, funding, scientific quality and bibliometrics. Int Orthop. 2018. https://doi.org/10.1007/s00264-018-4175-5.

61. Naziri Q, Burekhovich SA, Mixa PJ, Pivec R, Newman JM, Shah NV, et al. The trends in robotic-assisted knee arthroplasty: a statewide database study. J Orthop. 2019;16:298-301. https://doi.org/10.1016/j.jor.2019.04.020.

62. Kwon HM, Yang IH, Lee WS, Yu AR, Oh SY, Park KK. Reliability of intraoperative knee range of motion measurements by goniometer compared with robot-assisted arthroplasty. J Knee Surg. 2019;32:233-8. https://doi.org/10.1055/s-0038-1641140.

63. Iñiguez M, Negrín R, Duboy J, Reyes NO, Díaz R, et al. J Knee Surg. 2019; undefined (undefined), undefined. https://doi.org/10.1055/s-0039-1698771.

64. Casper M, Mitra R, Khare R, Jaramaz B, Hamlin B, McGinley B, et al. Accuracy assessment of a novel image-free handheld robot for Total knee Arthroplasty in a cadaveric study. Comput Assist Surg (Abingdon). 2018; 23(1):14-20. https://doi.org/10.1080/24699322.2018.1519038.

65. Citak M, Suero EM, Citak M, Dunbar NJ, Branch SH, Conditt MA, et al. Unicompartmental knee arthroplasty: is robotic technology more accurate than conventional technique? Knee. 2013;20(4):268-71. https://doi.org/10. 1016/j.knee.2012.11.001.

66. Karia M, Masjedi M, Andrews B, Jaffry Z, Cobb J. Robotic assistance enables inexperienced surgeons to perform unicompartmental knee arthroplasties on dry bone models with accuracy superior to conventional methods. Adv Orthop. 2013;2013:481039. https://doi.org/10.1155/2013/481039.

67. Becker R, Mauer C, Stärke C, Brosz M, Zantop T, Lohmann CH, et al. Anteroposterior and rotational stability in fixed and mobile bearing unicondylar knee arthroplasty: a cadaveric study using the robotic force sensor system. Knee Surg Sports Traumatol Arthrosc. 2013;21(11):2427-32. https://doi.org/10.1007/s00167-012-2157-5.

68. Dunbar NJ, Roche MW, Park BH, Branch SH, Conditt MA, Banks SA. Accuracy of dynamic tactile-guided unicompartmental knee arthroplasty. J Arthroplast. 2012;27(5):803-8.e1. https://doi.org/10.1016/j.arth.2011.09.021.

69. Pearle AD, O'Loughlin PF, Kendoff DO. Robot-assisted unicompartmental knee arthroplasty. J Arthroplast. 2010;25(2):230-7. https://doi.org/10.1016/j. arth.2008.09.024

70. Rodriguez F, Harris S, Jakopec M, Barrett A, Gomes P, Henckel J, et al. Robotic clinical trials of uni-condylar arthroplasty. Int J Med Robot. 2005;1(4): 20-8. https://doi.org/10.1002/rcs.52.

71. Marcovigi A, Zambianchi F, Sandoni D, Rivi E, Catani F. Robotic-arm assisted partial knee arthroplasty: a single centre experience. Acta Biomed. 2017;88: 54-9. https://doi.org/10.23750/abm.v88i2-S.6514.

72. Burger JA, Kleeblad L, Laas N, Pearle AD. Mid-term survivorship and patient-reported outcomes of robotic-arm assisted partial knee arthroplasty. Bone Joint J. 2020;null(1):108-16. https://doi.org/10.1302/0301-620X.102B1. BJJ-2019-0510.R1.

73. Zambianchi F, Franceschi G, Rivi E, Banchelli F, Marcovigi A, Khabbazè C, et al. Clinical results and short-term survivorship of robotic-arm-assisted medial and lateral unicompartmental knee arthroplasty. Knee Surg Sports Traumatol Arthrosc. 2020;28(5):1551-9. https://doi.org/10.1007/s00167-019-05566-4.

\section{Publisher's Note}

Springer Nature remains neutral with regard to jurisdictional claims in published maps and institutional affiliations.

Ready to submit your research? Choose BMC and benefit from:

- fast, convenient online submission

- thorough peer review by experienced researchers in your field

- rapid publication on acceptance

- support for research data, including large and complex data types

- gold Open Access which fosters wider collaboration and increased citations

- maximum visibility for your research: over $100 \mathrm{M}$ website views per year

At BMC, research is always in progress.

Learn more biomedcentral.com/submissions 